\title{
Screening for coronary heart disease risk factors in retail pharmacies in Sheffield, 1992
}

\author{
Cathy Allison, Hilary Page, Steve George
}

\begin{abstract}
Objective - To investigate the current and likely future provision of screening services for risk factors for coronary heart disease in retail pharmacies in Sheffield.

Design - This was a questionnaire survey asking about screening tests currently offered, price charged per test, likely future provision of screening tests, the action respondents would take upon finding an abnormal test result, whether the pharmacy was owner-run, franchised, or part of a commercial chain, and inviting open comments from respondents.

Setting - All retail pharmacy premises on the Sheffield Family Health Services Authority list.

Results - Seventy seven responses were obtained to 102 questionnaires distributed. Only nine of these currently offered any screening test other than pregnancy testing, although 37 indicated that they might offer tests in the future. Thirty nine were not offering screening and had no plans to do so. Pharmacies offering or likely to offer screening tests were mainly owner-run. All pharmacists who replied to the question asking about their action upon finding an abnormal result (33) reported that they would advise the patient to see a doctor. The most frequent comments made by pharmacists were about the commercial viability of screening in pharmacies and the lack of space available to ensure patient privacy and confidentiality during screening. Conclusions - Screening in retail pharmacies would probably be a commercial failure unless doctors were able to contract for screening services from pharmacies. Evidence from this study and others, however, leads us to question the desirability of this option.
\end{abstract}

\section{( $\mathcal{E}$ Epidemiol Community Health 1994;48:178-181)}

The past few years have seen moves to extend the role of retail pharmacists beyond the traditional dispensing of medicines. The Nuffield Foundation Committee of Inquiry into Pharmacy, reporting in $1986,{ }^{1}$ and the government white paper on primary health care of the following year ${ }^{2}$ proposed extending the role of community pharmacists into health education and screening, increasing their role in advising about minor illness, supervising medication in nursing homes for the elderly, and advising general practitioners about cost effective pre- scribing. In 1990 a joint working party was set up between the Department of Health and the Royal Pharmaceutical Society "to consider ways in which the National Health Service community pharmaceutical services might be developed to increase their contribution to health care, and to make recommendations". The working party reported in 1992, and produced a series of 30 recommendations. ${ }^{3}$ Recommendation 23 states: "We recommend that community pharmacies should continue to contribute to health promotion by offering diagnostic and screening services, within a framework of proper professional standards and safeguards, and that public funding should be introduced where such tests are provided at the request of a doctor or on behalf of a health authority." These recommendations have been recently summarised by the National Association of Health Authorities and Trusts. ${ }^{4}$

Sheffield Local Pharmaceutical Committee has produced a proposal that a number of screening tests primarily related to coronary heart disease prevention should be made routinely available in retail pharmacies in Sheffield. ${ }^{5}$ These included plasma cholesterol testing, blood pressure measurement, body mass index determination, body fat assessment, measurement of carbon monoxide in expired air, and blood glucose measurement. We decided to investigate the current and likely future provision of these services.

\section{Methods}

We designed a questionnaire, aimed at retail pharmacists, which requested details of screening tests currently offered, based upon the list of tests proposed by the Sheffield Local Pharmaceutical Committee, and including onsite pregnancy testing (but excluding the sale of commercial self-testing kits) as a baseline. We asked the price charged per test, whether tests currently offered would be offered in the future, and whether, in addition, any new tests would be offered. We also asked what action respondents would take upon finding an abnormal test result, and whether the pharmacy was owner-run, franchised, or part of a commercial chain. In addition, we included an open item which asked respondents to give their views on screening in pharmacies and on community pharmacy in general.

In March 1992 we piloted the questionnaire in three local pharmacies to ensure face validity and ease of completion, and in April 1992 we distributed it to all retail pharmacy outlets listed on the Sheffield Family Health Services Authority register. We sent a reminder to non- 
respondents within two weeks of the original questionnaire. We analysed the data using the Epi-info epidemiology computer program, grouping as far as possible the individual responses to the open question for analysis. We then attempted to interview by telephone those respondents currently offering screening to determine in greater detail their views on the subject of coronary heart disease screening in pharmacies.

Table 1 Number ( $\%$ ) of pharmacists currently offering screening services and mean price charged per test ( $n=77$; categories not mutually exclusive)

\begin{tabular}{llll}
\hline Test & No & $(\%)$ & Mean price \\
\hline Pregnancy testing & 57 & $(74)$ & $£ 4.70$ \\
Blood cholesterol testing & 3 & $(4)$ & $£ 10.00$ \\
Measurement of blood pressure & 7 & $(9)$ & $£ 0.75$ \\
Body mass index & 2 & $(3)$ & Free \\
Body fat assessment & 1 & $(1)$ & Free \\
Carbon monoxide in expired air & 0 & $(0)$ & N A \\
Blood glucose urine sugar & 4 & $(5)$ & $£ 3.75$ \\
Any other screening tests* & 2 & $(3)$ & N A \\
Any test except pregnancy & 9 & $(12)$ &
\end{tabular}

* One respondent offered weight and height measurement separately. The other offered serum triglyceride measurement in addition to cholesterol testing, and also offered haemoglobin and uric acid measurement.

Table 2 Number (\%) of pharmacists who might offer screening services in the future $(n=77$; categories not mutually exclusive)

\begin{tabular}{lrr}
\hline Test & $N o$ & $(\%)$ \\
\hline Pregnancy testing & 63 & $(82)$ \\
Blood cholesterol testing & 29 & $(38)$ \\
Measurement of blood pressure & 31 & $(40)$ \\
Body mass index & 14 & $(18)$ \\
Body fat assessment & 12 & $(16)$ \\
Carbon monoxide in expired air & 11 & $(14)$ \\
Blood glucose urine sugar & 26 & $(34)$ \\
Any other screening tests* & 5 & $(6)$ \\
Any test except pregnancy & 37 & $(48)$
\end{tabular}

* Two respondents are as reported in table 1. Although they stated that they might offer other tests, the remaining three respondents did not specify the tests concerned.

Table 3 Number of respondents in relation to category of ownership, whether offering any screening tests now, and whether planning to offer tests in future (figures in brackets in column one indicate percentages of total respondents; figures in brackets in columns two, three, and four indicate percentages of figures in column one, and are not mutually exclusive)

\begin{tabular}{lcllc}
\hline & $\begin{array}{l}\text { No (\%) of } \\
\text { respondents }\end{array}$ & $\begin{array}{l}\text { No(\%) } \\
\text { screening now }\end{array}$ & $\begin{array}{l}\text { No(\%) } \\
\text { screening in } \\
\text { future }\end{array}$ & $\begin{array}{l}\text { No(\%) } \\
\text { screening }\end{array}$ \\
\hline $\begin{array}{l}\text { Single owner, } \\
\text { owner response }\end{array}$ & $31(41)$ & $7(23)$ & $20(65)$ & $11(35)$ \\
$\begin{array}{l}\text { Single owner, } \\
\text { manager response }\end{array}$ & $3(4)$ & $1(33)$ & $2(67)$ & $1(33)$ \\
$\begin{array}{l}\text { Franchised } \\
\text { Chain }\end{array}$ & $10(13)$ & $1(10)$ & $6(60)$ & $4(40)$ \\
$\begin{array}{l}\text { Missing data } \\
\text { Total }\end{array}$ & $32(42)$ & $0(0)$ & $9(28)$ & $23(72)$ \\
\hline
\end{tabular}

* Very little data provided on form. The respondent indicated neither current nor future intention to provide screening, and was not part of a commercial chain or franchise.

Table 4 Number (\%) of pharmacists who, if an abnormality was found on any of these screening tests, would...

\begin{tabular}{lrr}
\hline & No & $(\%)$ \\
\hline Tell the patient of the abnormality & 16 & $(48)$ \\
Repeat the test & 27 & $(82)$ \\
Give verbal or written advice & 28 & $(85)$ \\
Advise patient to see GP & 31 & $(94)$ \\
Advise patient to see another doctor & 2 & $(6)$ \\
(Advise to see GP or other doctor) & 33 & $(100)$ \\
None of the above & 0 & $(0)$ \\
Total responses to question & 33 & $(100)$ \\
\hline
\end{tabular}

\section{Results}

One hundred and two questionnaires were distributed, and after one reminder 77 replies were received $(75 \%)$. Of the 77 respondents, only nine $(12 \%)$ were currently offering any screening test other than pregnancy testing. Details of individual tests are given in table 1 . Altogether $37(48 \%)$ pharmacies indicated that they might offer screening tests in the future (table 2$)$. Thirty nine $(51 \%)$ were not currently offering screening tests other than pregnancy testing, and indicated no plans to do so. Table 3 gives the number of respondents in relation to category of ownership, and shows that pharmacies offering screening were primarily owner-run: no pharmaceutical chains currently offered screening, and only nine of 32 $(28 \%)$ might offer screening in future. This compared with seven of $31(23 \%)$ owner-run pharmacies currently offering screening, and 20 of $31(65 \%)$ that might offer screening in the future.

Table 4 shows the results of the question which asked for the pharmacists' reaction to an abnormal result on a screening test. Thirty three participants answered this question. All belonged to the group who offered screening currently or who might do so in future. Approximately half (16: $49 \%$ ) reported that they would tell the patient of the abnormality. Thirty one $(94 \%)$ reported that they would advise a patient to see his or her general practitioner in the event of an abnormal result, and the remaining two respondents $(6 \%)$ reported that they would advise the patient to see another medical practitioner, in both cases a hospital consultant. Twenty eight $(85 \%)$ stated that they would give the patient verbal or written advice upon the finding of an abnormality. Twenty seven $(82 \%)$ reported that they would repeat the test.

Fifty four responded to the invitation to comment upon community pharmacy and upon screening within retail pharmacy. These comments are given in table 5 . The most frequent comment received concerned the funding of screening. Fifteen of the 37 pharmacists currently offering screening or planning to do so in the future questioned its commercial viability in pharmacies, as did four of the 39 pharmacists not planning to offer screening. Ten of the 37 pharmacies offering screening currently or in future mentioned lack of space available to ensure patient privacy and confidentiality during screening, as did one of the 39 not planning to offer screening. Five of the 37 who offer screening currently or plan to do so in the future commented upon the lack of time or staff available to undertake screening, as did three of the 39 not planning to offer screening. A variety of other comments was made by smaller numbers of respondents, and included mention of the lack of public demand for screening, the need for training in counselling skills, and doubts as to whether screening was beneficial.

Seven of the nine individuals currently offering screening were able to be contacted by telephone. A list of their comments is provided in table 6. Of particular interest were the 
Table 5 Views and additional information offered by 54 respondents in response to an open question on the provision of screening in retail pharmacies (categories not mutually exclusive)

\begin{tabular}{ll}
\hline & $\begin{array}{l}\text { No (\%) } \\
\text { expressing view }\end{array}$ \\
\hline $\begin{array}{l}\text { Not commercially viable/public funding } \\
\text { needed }\end{array}$ & $19(35)$ \\
$\begin{array}{l}\text { Lack of space available to ensure patients' } \\
\text { privacy/capital investment needed to alter } \\
\text { premises }\end{array}$ & $11(20)$ \\
$\begin{array}{l}\text { No time available to perform screening } \\
\text { tests/more staff needed }\end{array}$ & $8(15)$ \\
$\begin{array}{l}\text { No demand from public } \\
\text { Training required for counselling/difficult to } \\
\text { know what to do with abnormal findings }\end{array}$ & $3(6)$ \\
$\begin{array}{l}\text { Screening not the function of the } \\
\text { pharmacist/not best use of pharmacist's } \\
\text { time/should be done by doctor }\end{array}$ & $3(6)$ \\
$\begin{array}{l}\text { Not sure whether screening is beneficial } \\
\text { Company policy not to screen }\end{array}$ & $2(4)$ \\
$\begin{array}{l}\text { Useful to establish credibility of local } \\
\text { pharmacists }\end{array}$ & $2(4)$ \\
$\begin{array}{l}\text { Price of test given } \\
\text { Referral doctor identified }\end{array}$ & $1(2)$ \\
\hline
\end{tabular}

comments received from the three pharmacists currently offering cholesterol screening. All indicated their intention to continue offering cholesterol screening, but two indicated that they would not offer cholesterol screening if they had not already invested in the equipment to do so. One reported that after an initial burst of activity, requests for testing had dwindled to nothing, and that he had not performed a cholesterol test for several months. Another indicated that he would favour a voucher scheme which would enable patients to purchase screening tests.

\section{Discussion}

With the exception of pregnancy testing, used here as a baseline, all the tests recommended in the Sheffield Local Pharmaceutical Committee document are aimed at reducing cardiovascular disease risk. Blood glucose or urine sugar testing could be used to identify people with diabetes, itself a predictor of high coronary heart disease mortality. On first examination, the provision of coronary heart disease risk factor screening in retail pharmacies has many potential advantages. There is the opportunity for screening to be offered to a much larger population than that which regularly visits a doctor's surgery. A large number of people visit pharmacy premises each day, often for reasons which do not include current ill health, and pharmacies are often more conveniently situated than doctors' surgeries. It has been

Table 6 Comments received from seven respondents currently offering cholesterol screening (respondents 1-3 offering cholesterol testing)

1 - There's been a poor response to cholesterol testing really, but it's been set up so we'll continue to do it. One or two tests a week at the beginning, but none for the last few months.

2 - We'll continue with cholesterol testing, although we're very rarely asked, and without referral from doctors I don't think it's viable. It was fashionable at one time, but not now. There's no interest in repeating tests.

3 - Cholesterol testing hasn't been bad, but I think that charges limit its use. The people who are most in need probably can't afford it. I would like to see a voucher scheme to give patients choice.

4- The public's attitude is "we don't need to know if we're ill until it happens". Things may be different in Utopia, but it's not like that in Sheffield.

5 - I think the pharmacist has a role in doing these tests but $I$ hope that funds are available.

6 - I think provision of screening services would only be viable from about two centres in Sheffield.

7 - I test weight and height already, and I might offer a reflotron. However, further involvement would need funding from the Family Health Services Authority or anothe body. suggested that the health education role of the pharmacist should be enhanced, ${ }^{6}$ and advice given by pharmacists to help patients to stop smoking has been found to be effective. ${ }^{7}$

However, it is worth considering both the usefulness of the tests offered and the practicalities of screening in retail pharmacies. Taking body mass index and body fat assessment as the first example, although clinical obesity is clearly related to coronary heart disease, ${ }^{8}$ the British Regional Heart Study found no relationship between body mass index and cardiovascular disease on a town basis, ${ }^{9}$ and a slight positive effect when individuals were observed prospectively. ${ }^{10}$ Rather, it was a recent change in the body mass index which was a predictor of cardiovascular disease. It is difficult to see how this can be measured in a pharmacy without the setting up of a patient register similar to that operated by a general practitioner. No such registration system was proposed in the Sheffield Local Pharmaceutical Committee document.

Despite the fact that no pharmacists were currently providing measurement of carbon monoxide in expired air, 11 were considering doing so. However, it is hard to see what this measurement would provide. It can only tell the pharmacist and the patient whether or not the patient smokes, a fact which should be obvious to the patient already, and which should not affect the provision of smoking advice. Its main use, therefore, remains in the context of "smokestop" groups as an indicator to the rest of the group that an individual has, or has not, refrained from smoking tobacco.

Turning our attention to plasma cholesterol screening, $35 \%$ of those pharmacists who gave their opinions in this study $(25 \%$ overall $)$ believed screening in pharmacies to be uneconomic unless funded from central resources, and two of the three currently providing cholesterol screening indicated that they would not initiate such a service again. Individual patients are likely to find the price of $£ 10.00$ per test prohibitive. There is a high chance that any such venture will be a commercial failure, therefore, unless doctors contracted for the provision of screening services from pharmacies.

Several other factors also need to be taken into consideration. First, it should be noted that while it is straightforward to maintain quality control within a centralised laboratory, it is hard to envisage an easy way to do this in a disparate arrangement of testing machines spread over a number of sites. A recent British study investigating the reliability of desk top analysers ${ }^{11}$ found that a general practitioner using such a machine would not be able to distinguish reliably between a cholesterol level of $5.2 \mathrm{mmol} / 1$ and one of $6.5 \mathrm{mmol} / 1$ - two of the action limits proposed by the British Hyperlipidæmia Association and the European Atherosclerosis Society. ${ }^{1213}$ The same study found that two common sources of error in measurement were poor technique and the use of outdated reagent strips, both of which are likely to be problems in retail pharmacies where demand for testing, as in this study, is 
low. Tunstall-Pedoe ${ }^{14}$ recommends that three or more readings of plasma cholesterol are necessary to establish a baseline to monitor change. It is unclear how this could be ensured in a service dictated primarily by patient demand, which relies upon results from desk top analysers, and where there is no patient registration system. Similar considerations apply to the provision of blood pressure testing, where it is generally accepted that a firm diagnosis of hypertension should not be made on a single random measurement.

Second, there has been little consideration of the facilities needed for the taking of blood samples for cholesterol testing. The second most common comment made by pharmacists was that they had insufficient space to ensure patient privacy during testing, and a major programme of capital investment into retail pharmacy is unlikely to be funded centrally.

Third, there is an element of risk involved with the taking of blood samples. At present there is a register of all businesses involved in skin piercing practices, including ear piercing, tattooing, acupuncture, and electrolysis, and clear standards of practice are enforced. However, agencies offering cholesterol testing are not included on the register.

Fourth, all those pharmacists who replied to the question about their action upon finding an abnormal result reported that they would advise the patient to see a doctor. Given the inaccuracy of desk top testing apparatus, this suggests that the number of inappropriate referrals to general practitioners is likely to rise considerably.

Most general practitioners, in a survey of their attitudes to extended roles for community pharmacists, disagreed with the suggestions that pharmacists should screen for raised blood pressure, raised blood lipids, or height and weight in schoolchildren. ${ }^{15} \mathrm{~A}$ recent meta-analysis of results of cholesterol lowering treatments concluded that "population screening for isolated raised cholesterol concentrations, whether in the high street or in the general practitioner's surgery, is not currently indicated". ${ }^{16}$ This is echoed in the recent Health of the Nation key area handbook on coronary heart disease and stroke, which recommended a case finding approach rather than systematic screening, with testing focused on priority groups with other risk factors for coronary heart disease. ${ }^{17}$

This survey indicates that public interest in screening, particularly cholesterol screening, is low, and that funds would have to be made available either from central sources or from general practitioners to make it commercially viable. However, the lack of funding for health education activity in pharmacies has been commented upon previously, ${ }^{6}$ and it is unlikely that screening in pharmacies would be given central support. Moreover, the public may be right. It is questionable whether the provision of screening for coronary heart disease risk factors in retail pharmacies is either necessary or desirable.

This study was carried out during a student elective period at the Medical School of the University of Sheffield, and we are grateful to the Medical School and to Professor Brian Williams frateful to the Mroviding financial support to the study.

We would like to thank all those who shared their views with us in this study, and we would like to thank Sheffield Family us in this study, and we would like to thank Sheffield Family
Health Services Authority for their help in identifying retail Health Services Author
pharmacies in Sheffield.

1 Nuffield Foundation Committee of Inquiry. Pharmacy: the report of a committee of inquiry appointed by the Nuffield Foundation. London: Nuffield Foundation, 1986

2 Secretaries of State for Health, Wales, Scotland and Northern Ireland. Promoting better health. London: HMSO, 1987.

3 Joint Working Party of the Department of Health and the Royal Pharmaceutical Society. Pharmaceutical care: the future for community pharmacy. London: Royal Pharmafuture for community phat
ceutical Society, 1992 .

4 National Association of Health Authorities and Trusts. The future of community pharmacy. Birmingham: NAHAT, December 1992. Briefing No 37 .

5 Sheffield Local Pharmaceutical Committee. The way forward for community pharmacy in Sheffield. Sheffield: Sheffield Local Pharmaceutical Committee, 1991.

6 Maguire T. Is the community pharmacist a health educator? Pharmaceutical fournal 1990;245:556-9.

7 Maguire T. A study of the feasibility of a smoking cessation service in a community pharmacy. Pharmaceutical fournal (Suppl) 1993;251:R26

8 Morris JN, Kagan A, Pattison DC, Gardner MJ, Raffle PAB. Incidence and prevalence of ischaemic heart disease in London busmen. Lancet 1966;ii:553-9.

9 Shaper AG, Pocock SJ, Walker M, Cohen NM, Wale CJ, Thomson AG. British Regional Heart Study: cardiovascular risk factors in middle-aged men in 24 towns. BMF 1981;283:179-86.

10 Shaper AG, Pocock SJ, Walker M, Philips AN, Whitehead TP, Macfarlane PW. Risk factors for ischaemic heart Tisease: the prospective phase of the British Regional disease: the prospective phase of the British Regional
Heart Study. $\mathcal{J}$ Epidemiol Community Health Heart Study.

11 Broughton PMG, Bullock DG, Cramb R. Quality of plasma cholesterol measurements in primary care. $B M \mathcal{F}$ 1989;298:297-8.

12 Shepherd J, Betteridge DJ, Durrington P, et al. Strategies for reducing coronary heart disease and desirable limits for blood lipid concentration. BMF 1987;295:1245-6.

13 European Atherosclerosis Society. The recognition and management of hyperlipidæmia in adults: a policy statemanagement of hyperlipidæmia in adults: a policy statement of the Europ

14 Tunstall-Pedoe $\mathrm{H}$. Who is for cholesterol testing? BMF 1989;298:1593-4.

15 Spencer JA, Edwards C. Pharmacy beyond the dispensary: general practitioner's views. BMF 1992;304:1670-2.

16 Davey Smith G, Song F, Sheldon TA. Cholesterol lowering and mortality: the importance of considering initial level of risk. $B M \mathcal{Y}$ 1993;306:1367-73.

17 Department of Health. The health of the nation: key area handbook on coronary heart disease and stroke. Heywood BAPS Health Publications Unit, 1993. 